\title{
The Evaluation of Surface Integrity During Machining of Inconel 718 with Various Laser Assistance Strategies
}

\author{
Szymon Wojciechowski ${ }^{1, a}$, Damian Przestacki $^{1}$ and Tadeusz Chwalczuk ${ }^{1}$ \\ ${ }^{1}$ Poznan University of Technology, Institute of Mechanical Technology, Piotrowo 3, Poznan 60-965, Poland
}

\begin{abstract}
The paper is focused on the evaluation of surface integrity formed during turning of Inconel 718 with the application of various laser assistance strategies. The primary objective of the work was to determine the relations between the applied machining strategy and the obtained surface integrity, in order to select the effective cutting conditions allowing the obtainment of high surface quality. The carried out experiment included the machining of Inconel 718 in the conventional turning conditions, as well as during the continuous laser assisted machining and sequential laser assistance. The surface integrity was evaluated by the measurements of machined surface topographies, microstructures and the microhardness. Results revealed that surface integrity of Inconel 718 is strongly affected by the selected machining strategy. The significant improvement of the surface roughness formed during machining of Inconel 718, can be reached by the application of simultaneous laser heating and cutting (LAM).
\end{abstract}

\section{Introduction}

Super alloys based on the nickel, including Inconel 718 are materials which are characterized by the unique properties, as: excellent strength at the elevated temperatures, increased thermal conductivity, as well as resistance to oxidation and corrosion at the high temperatures. Thus, these materials are being widely applied in the aircraft, turbine and nuclear power plant applications. According to Ezugwu [1] the aerospace engine component is made of nickel-based alloys in about $50 \%$ of its weight. Nevertheless, these excellent properties of super alloys significantly affect their machinability. The primary problems occurring during machining of Inconel alloys include the: high values of forces, the concentration of heat, tool fracture induced by plastic deformation during cutting with higher speeds, the decreased tool life and the work hardening phenomenon [2]. Therefore the nickel based super alloys are the materials which are difficult-to-cut.

Literature survey shows that many researches are focused on improvement of machinability by the application of high-pressure cooling [3], plasma enhanced machining [4, 5], laser assisted machining (LAM) [6-8]. However, according to Venkatesan et al. [9], the laser assisted machining is an approach which gives increased benefits without compromising quality, in comparison to other novel technologies. The LAM technology is based on the application of high power laser, which heats the workpiece before the initiation of chip removal induced by a tool [10]. The aim of the process is to reduce the cutting forces by an increase of machining temperature, which leads to the reduction of the material's strength. The main advantages of the LAM are: improvement in surface roughness, decrease in specific cutting energy, growth of material removal rates, improvement of process stability and reduction of tool's catastrophic fracture and wear [11-13]. The application of LAM during machining of Inconel significantly enhances its machinability. Nevertheless, the improvement of machined surface integrity requires the selection of the appropriate cutting conditions and strategies. The machined surface integrity is affected by the kinematic-geometric parameters, process stability [14] and vibrations $[15,16]$, plastic-elastic deformations of work material induced by the ploughing mechanism [17], as well as the thermal phenomena in the cutting zone [18]. However, in case of difficult-to-cut materials, the effective application of LAM can result in improvement of machined surface quality. According to Przestacki et al. [19], the application of LAM during turning of MMC composite induces the sedimentation of hard $\mathrm{SiC}$ particles and thus causes the decline in surface roughness. In addition, the LAM of Inconel 718 in the appropriately selected temperature of the cutting zone can contribute to the decrease of tool wear rate and thus to the improvement of surface roughness [20].

The literature survey reveals that LAM of difficult-to-cut materials has been extensively investigated by many researchers [21]. However, the problems of machined surface integrity formed during LAM of Inconel 718, considering the cutting strategy have not been investigated sufficiently. Therefore this paper is focused on the relations between the applied laser assisted machining strategy and the obtained surface integrity. The conducted machining tests involved the following strategies: conventional turning (without laser assistance), sequential process with laser heating prior to turning and simultaneous laser heating and cutting (LAM). The obtained results can be applied for the selection of the effective cutting conditions allowing the improvements in surface finish.

\footnotetext{
${ }^{\mathrm{a}}$ Corresponding author : sjwojciechowski@o2.pl
} 


\section{Experimental details}

\subsection{Workpiece and cutting tool}

The Inconel 718 super alloy was applied as the workpiece. Its chemical composition is depicted in Table 1. The workpieces were provided as a cylinders with a diameter of $44 \mathrm{~mm}$. The sample's microstructure consists mainly of $\gamma$ solid solution grains, as well as the visible intermetallic phases, probably $\gamma^{\prime}$ and $\gamma^{\prime}$.'

Table 1. Chemical composition of Inconel 718 [\%]

\begin{tabular}{cc}
\hline \hline Element & Content \\
\hline $\mathrm{Ni}$ & $50-55$ \\
$\mathrm{Cr}$ & $17-21$ \\
$\mathrm{Nb}$ & $4.75-5.5$ \\
$\mathrm{Mo}$ & $2.8-3.3$ \\
$\mathrm{Ti}$ & $0.65-1.15$ \\
$\mathrm{Al}$ & $0.2-0.8$ \\
$\mathrm{Co}$ & 1 \\
$\mathrm{Mn}$ & 0.35 \\
$\mathrm{Si}$ & 0.35 \\
$\mathrm{Cu}$ & 0.3 \\
$\mathrm{C}$ & 0.08 \\
$\mathrm{P}$ & 0.015 \\
$\mathrm{~S}$ & 0.015 \\
$\mathrm{~B}$ & 0.006 \\
$\mathrm{Fe}$ & $\mathrm{Bal}$. \\
\hline \hline
\end{tabular}

The samples dedicated to LAM were covered with a gouache layer in order to increase the absorption of laser's beam. The conventional and laser assisted turning tests (LAM) were carried out with the application of the coated sintered carbide KC5510 inserts with the SNMG120408 MS symbol and the following geometry: tool major cutting edge angle $\mathrm{\kappa r}=45^{\circ}$, flank angle in the feed motion direction $\alpha \mathrm{f}=5^{\circ}$, rake angle in the feed motion direction $-\gamma \mathrm{f}=-5^{\circ}$ and tool radius $\mathrm{r} \varepsilon=0.8 \mathrm{~mm}$.

\subsection{Machining tests}

The carried out experiments (see - Tab. 2) involved the conventional longitudinal turning process (without laser assistance, designated as S4), laser assisted machining (LAM) including the simultaneous laser heating and turning of the heated surface (designated as S1 and S3), and sequential process which consisted of the heating of workpiece, its cooling down and then, turning (designated as S2).

Table 2. Design of experiment

\begin{tabular}{ccccccc}
\hline \hline No & $\begin{array}{c}\text { Laser power } \\
P[\mathrm{~W}]\end{array}$ & $\begin{array}{c}\text { Laser spot } \\
\text { diameter [mm }]\end{array}$ & $\begin{array}{c}\text { Depth of cut } \\
a_{p}[\mathrm{~mm}]\end{array}$ & $\begin{array}{c}\text { Feed } \\
f[\mathrm{~mm} / \mathrm{rev}]\end{array}$ & $\begin{array}{c}\text { Cutting } \\
\text { speed } \\
v_{c} \\
{[\mathrm{~m} / \mathrm{min}]}\end{array}$ & $\begin{array}{c}\text { Laser } \\
\text { scanning } \\
\text { speed } v_{l} \\
{[\mathrm{~mm} / \mathrm{min}]}\end{array}$ \\
\hline S1 & & & & & 5.8 & 5.8 \\
S2 & 1200 & 1 & 0.25 & 0.2 & 28 & 5.8 \\
S3 & & & & & 28 & 28 \\
S4 & 0 & & & & 28 & 0 \\
\hline \hline
\end{tabular}

The laser heating experiments were made on LAM stand equipped with Trumpf CO2 molecular laser integrated with TUM 35D1 lathe. The laser had the maximum power equaled to $2600 \mathrm{~W}$ and the radiation power density distribution type TEM01.

\subsection{Inspection of surface integrity}

The metallographic microsections of samples after machining were prepared in order to evaluate the microstructure and microhardness. These samples were mounted in the conductive resin, polished with the suspension, containing Al2O3, and ultimately etched in order to reveal their microstructure. The metallographic microsections of the machined samples were investigated with the application of a OPTA-TECH LAB-40 optical microscope and TESCAN scanning microscope, type VEGA TS 5135, equipped with an AWALON 4000 system. The hardness was determined with the application of Micromet II Buehler hardness meter.

The evaluation of surface topography was made with the application of T8000 stationary stylus surface profiler. The following settings were applied during the measurements: the sampling length equal to $0.8 \mathrm{~mm}$, the measurement length equal to $4.0 \mathrm{~mm}$. Based on the obtained surface profiles, the surface roughness parameters ( $\mathrm{Sa}, \mathrm{Sz}$ ) were calculated with the use of dedicated software. 


\section{Results and discussion}

Figure 1 depicts the comparison of the Inconel 718 alloy's microstructure after various machining strategies. The analysis of SEM images shows that the application of distinct machining strategies has no significant effect on the obtained microstructure of samples. In all cases, the slightly lower grain sizes in the area near the surface layer (Fig. 1a) were found, in comparison to those contained in the base (Fig. 1b). It should be also noted that during machining with laser assistance (S1, S2, S3), the whole remelted area has been probably totally removed by the cutting tool. Thus the SEM images presented in Fig. 1 are similar, independently on the applied machining strategy.

Despite the similar microstructure of samples, obtained after machining in various strategies, the distribution of microhardness along the radial direction reveals some differences (Fig. 2). In case of non-machined sample (M00), the microhardness oscillates around the $400 \mathrm{HV}$. However for the all machined samples, the decreasing trend of hardness values together with the growth of distance from the surface layer is observed. It is caused by the appearance of thermal phenomena, occurring in the shearing zone, resulting from the chip removal mechanisms. The variations in microhardness values, along the depth, reach up to $62 \%$. It should be noted, that in case of conventional turning (S4) and simultaneous laser assisted machining (S1 and S3), the distribution of microhardness is similar. The lack of differences between these distinct machining strategies is probably caused by a relatively low depth of area re-melted by the laser beam. In example, during LAM of metal matrix composite with laser power $\mathrm{P}=1000 \mathrm{~W}$, the depth of re-melted area is usually lower than $100 \mu \mathrm{m}$ [19]. Furthermore, the increase of cutting and laser scanning speeds during LAM induces the slight decline in microhardness values in the range of radial depths to approx. $250 \mu \mathrm{m}$ (see the hardness curves for the S1 and S3 in Fig. 2).

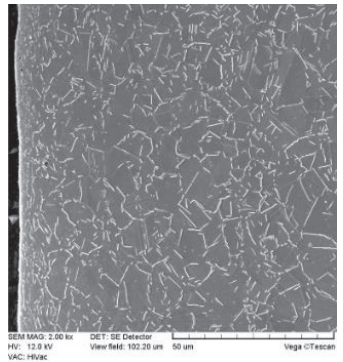

S1

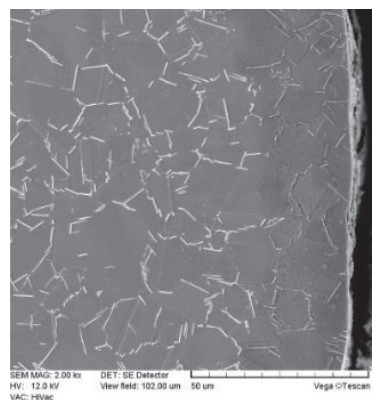

S1

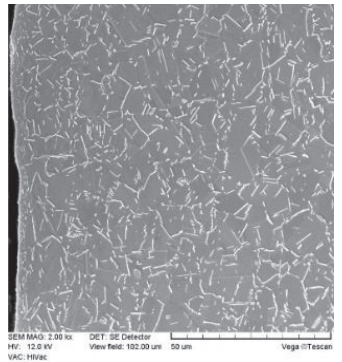

$\mathrm{S} 2$

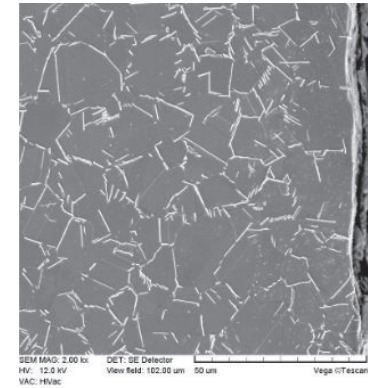

$\mathrm{S} 2$

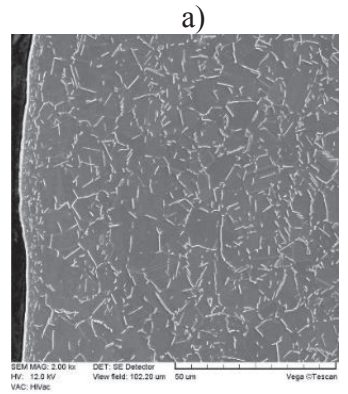

S3

b)

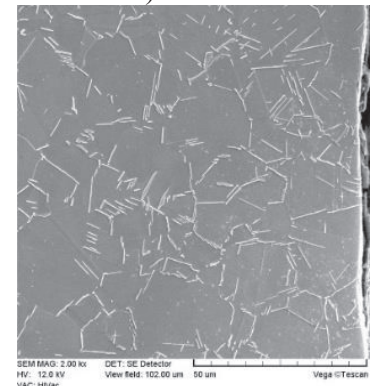

S3

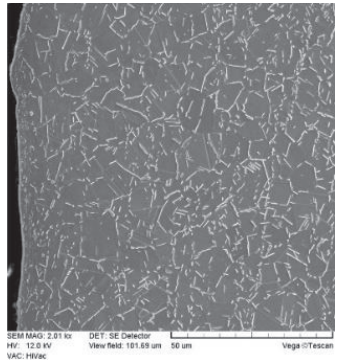

S4

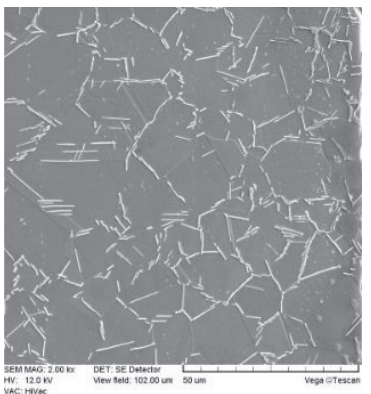

S4

Figure 1. The SEM images of the Inconel 718 samples after various machining strategies: a) microstructure in the area of surface layer; b) microstructure in the area of base.

Figure 3 shows also that the lowest microhardness values, in the whole investigated range of sample's depth are found after the sequential machining process (S2). In this case the cooling time of workpiece is being extended in comparison to that appearing during LAM process, because of lack of heated chip removal action. Consequently, the higher amount of heat is transferred into the workpiece, which leads to the decrease of its microhardness. The surface topographies, obtained during turning in the range of investigated strategies are presented in figure 3. It can be observed that for the S2-S4 samples, the regular and constant distance between the formed irregularities is found. Its value corresponds to feed per revolution ( $\mathrm{f}=0.2 \mathrm{~mm} / \mathrm{rev}$ ), and results from the kinematic-geometric model (so-called feed marks). Nevertheless, in case of S1 sample, machined in the LAM conditions with the lowest cutting speed and laser scanning speed, the distances between irregularities are variable, and thus the surface topography has a less regular form. This observation is strictly correlated with the lateral plastic flow of the overheated workpiece material, which in turn is attributed to the high heat transfer between the laser spot and workpiece's heated surface, occurring at the low cutting speed and laser scanning speed. Consequently the high heat transfer induces the growth of machined surface temperature and thus the intense softening of workpiece. 


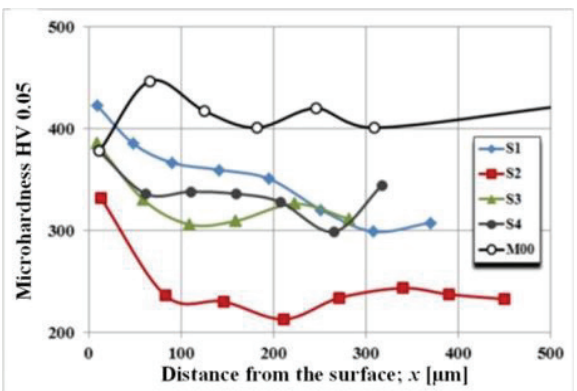

Figure 2. The distribution of microhardness in the investigated samples, along the radial direction from the surface layer.

In case of S4 sample, machined during conventional turning, some burrs are found on the peaks of formed irregularities. Their appearance can be related to the local brittle cracking of workpiece during material removal by the tool tip.

a)

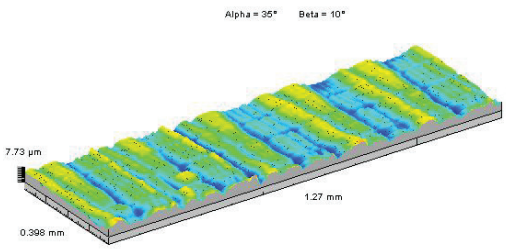

c)

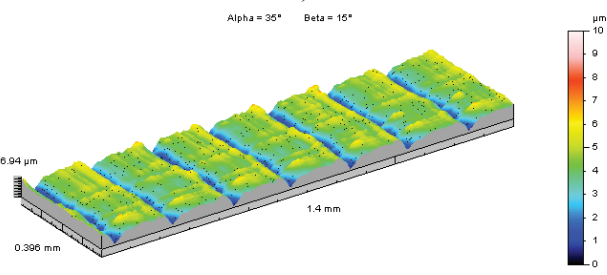

b)

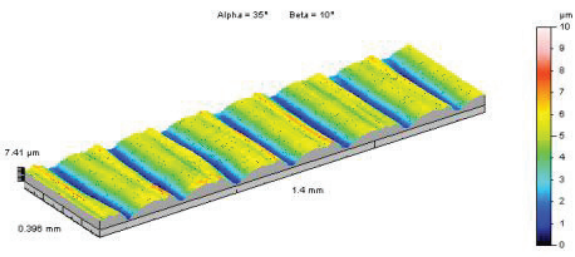

d)

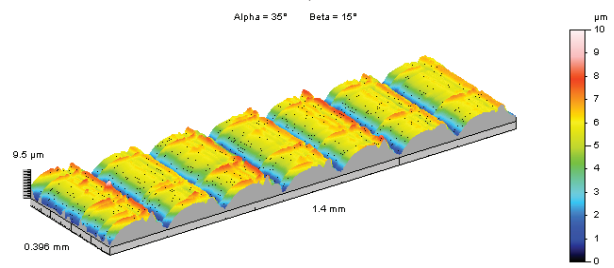

Figure 3. Surface topographies of Inconel 718 samples obtained during investigated turning strategies: a) S1; b) S2; c) S3; d) S4.

The analysis of surface roughness parameters (Figs. 4a,b) reveals also that the highest values of Sa and Sz are found for the S4 sample machined during conventional turning. The lowest surface roughness can be obtained during the laser assisted machining (LAM), including the simultaneous laser heating and turning of the heated surface (S1, S3). However, the application of sequential process enables the obtainment of surface roughness parameters ranked between the LAM and conventional machining.

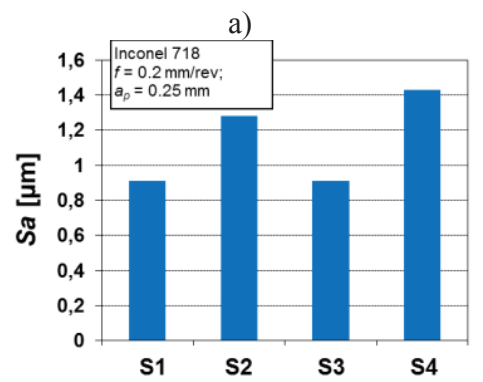

b)

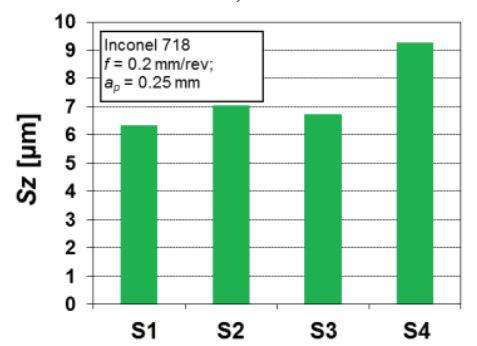

Figure 4. The comparison of surface roughness parameters obtained during turning with various strategies : a) $\mathrm{Sa}$; b) Sz.

\section{Conclusions}

The conducted research allowed to formulate the following conclusions:

- the distribution of microhardness in the Inconel 718 samples after turning is depended on the selected machining strategy. The lowest microhardness values in the whole investigated depth of sample can be reached during sequential process, which involves heating of workpiece, cooling down and then, turning;

- during LAM with the low cutting speed and laser scanning speed values, the overheating of the surface layer can be found, which results in the lateral plastic flow of the workpiece and thus formation of surface profile without the regular feed marks;

- in case of conventional turning of Inconel 718, the undesirable local brittle cracking of workpiece can occur, which affects the surface profile formation and thus the growth of surface roughness;

- the application of LAM improves the machined surface quality by the reduction of surface roughness parameters' values. The differences between the Sa values obtained during conventional turning and LAM reach up to 57\%. 


\section{Acknowledgment}

The presented research results, executed under the domestic project PBS of No 244445, were funded with grants for education allocated by the National Centre for Research and Development.

\section{References}

1. E.O. Ezugwu, Int. J. Adv. Manuf. Technol. 45 (2015)

2. D. Dudzinski, A. Devillez, A. Moufki, D. Larrouquere, V. Zerrouki, J. Vigneau, Int. J. Adv. Manuf. Technol. 44 (2004)

3. E. O. Ezugwu, J.Bonny, Tribol. Trans. 48 (2005)

4. C.E. Leshok, J. Kim, Y.C. Shin, Int. J. Mach. Tools Manuf. 4 (2001)

5. Z.Y. Wang, K.P. Rajurkar, J. Fan, S. Lei, Y.C. Shin, G. Petrescu, Int. J. Mach. Tools Manuf. 43 (2003)

6. P.A. Rebro, Y.C. Shin, F.P. Incropera, Int. J. Adv. Manuf. Technol. 44 (2004)

7. S. Lei, Y.C. Shin, F.P. Incropera, J. Manuf. Sci. Eng. Trans. ASME 123 (4) (2001)

8. M. Anderson, R. Patwa, Y.C. Shin, Int. J. Adv. Manuf. Technol. 48 (2006)

9. K. Venkatesan, R. Ramanujam, P. Kuppan, Optics \& Laser Technology 78 (2016)

10. P. Dumitrescu, P. Koshy, J. Stenekes, MA. Elbestawi, Int. J. Mach. Tools Manuf. 46 (2006)

11. D. Przestacki, M. Jankowiak, Journal of Physics: Conference Series 483 (2014)

12. D. Przestacki, Procedia CIRP 14 (2014)

13. S. Sun, M. Brandt, M.S. Dargusch, Int. J. Mach. Tools Manuf. 50 (2010)

14. R. Rusinek, M. Wiercigroch, P. Wahi, Procedia CIRP 31 (2015)

15. S. Wojciechowski, P. Twardowski, M. Pelic, R.W. Maruda, S. Barrans, G. Krolczyk, Precision Engineering 46 (2016)

16. S. Wojciechowski, P. Twardowski, M. Pelic, Procedia CIRP 14 (2014)

17. S. Wojciechowski, R.W. Maruda, P. Nieslony, G.M. Krolczyk, International Journal of Mechanical Sciences 119 (2016)

18. D. Przestacki, T. Chwalczuk, S. Wojciechowski, Int J Adv Manuf Technol, DOI 10.1007/s00170-017-0035-5 (2017)

19. D. Przestacki, P. Szymanski, S. Wojciechowski, Composites Part A: Applied Science and Manufacturing 911 (2016)

20. S. Azhdari Tadavani, R. Shoja Razavi, R. Vafaei, Optics \& Laser Technology 87 (2017)

21. D. Przestacki, L. Marciniak-Podsadna, R. Majchrowski, Applied Surface Science 388 (2016) 